Ulrike Einhorn-Stoll, Hanna Kastner, Theresia Hecht, Annett Zimathies, Stephan Drusch

\title{
Modification and physico-chemical properties of citrus pectin - Influence of enzymatic and acidic demethoxylation
}

Journal article | Accepted manuscript (Postprint)

This version is available at https://doi.org/10.14279/depositonce-9849

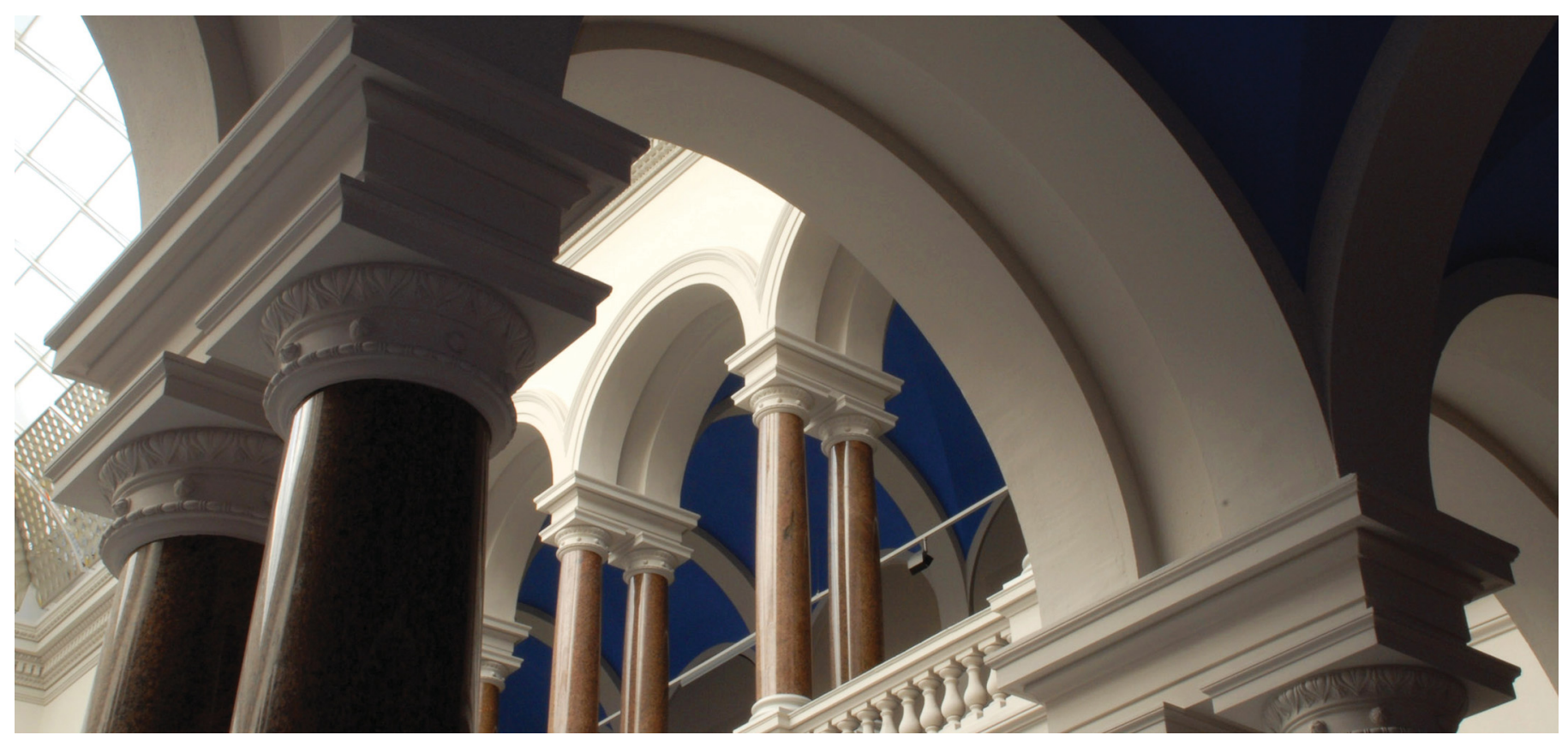

Einhorn-Stoll, U., Kastner, H., Hecht, T., Zimathies, A., \& Drusch, S. (2015). Modification and physicochemical properties of citrus pectin - Influence of enzymatic and acidic demethoxylation. Food Hydrocolloids, 51, 338-345. https://doi.org/10.1016/j.foodhyd.2015.05.031 


\title{
Modification and physico-chemical properties of citrus pectin - Influence of enzymatic and acidic demethoxylation
}

\author{
U. Einhorn-Stoll ${ }^{a}$, H. Kastner ${ }^{a}$, T. Hecht ${ }^{a}$, A. Zimathies ${ }^{b}$, S. Drusch ${ }^{a}$ \\ ${ }^{\text {T} T e c h n i s c h e ~ U n i v e r s i t a ̈ t ~ B e r l i n, ~ F o o d ~ T e c h n o l o g y ~ a n d ~ F o o d ~ M a t e r i a l ~ S c i e n c e, ~}$ \\ Königin-Luise-Strasse 22, D-14195 Berlin, Germany \\ ${ }^{\mathrm{b}}$ Federal Institute for Material Research and Testing, 1.3 Structure Analysis, \\ Richard-Willstätter-Str. 11, D-12489 Berlin, Germany
}

\section{Abstract}

Pectins are distributed as powders, they have to be suspended and dissolved before application. Beside the molecular parameters, such as degree of methoxylation (DM), also powder properties such as thermal degradation stability or water uptake ability determine their behaviour and application conditions.

Two groups of model pectins, one with DM 57\% and one with DM 42\%, have been prepared from one mother pectin (DM 68\%) under exactly defined conditions. They were modified by an acidic and two enzymatic methods. The enzymes were fungi (f) and plant ( $p$ ) pectinmethylesterases (PME). All pectins were treated similarly after demethoxylation. Thermal stability was tested by thermal analysis and water uptake by a sorption and a capillary sucking method.

The enzyme-treated pectins were less thermal stable than the acidic-treated and their water uptake was superior to the acidic-treated in the sorption method and inferior in the capillary sucking tests. The differing $\mathrm{pH}$ during demethoxylation (1.5 for acidic, 4.4 for fPME and 7.4 for pPME) caused varying intermolecular interactions of the pectin macromolecules in solution, resulting in different material properties after drying. Additionally, the distribution of free carboxyl groups (statistical or block-wise) had an influence on these properties. There was a significant correlation between thermal stability and water uptake by sorption. 


\section{Introduction}

Pectins are food hydrocolloids of high consumer acceptance and, therefore, ingredients in a wide range of food products. They can be tailored for specific applications by different modifications, demethoxylation from high-methoxylatd pectins (HMP) to low-methoxylated pectins (LMP) is the dominating process. The methoxyl group at $\mathrm{C}_{6}$ of the galacturonic acid ( $\left.\mathrm{Gal} A\right)$ units of the pectin molecule backbone is cleaved and a carboxyl group is formed. This was traditionally performed as a chemical reaction under acidic or alkaline conditions. Nowadays it is mainly an enzymatic process using fungi or plant pectinmethylesterases fPME or pPME (Rolin, 2002; Rolin, Chrestensen, Hansen, Staunstrup \& Sorensen, 2010) with only limited side reactions, such as depolymerisation, and because it allows a better process control. The application of plant PME for the modification of pectins for the milk industry in acidic dairy drinks (Laurent \& Boulenguer, 2003) was an additional example for the application of the enzymes. Whereas chemical demethoxylation and most fPME, which are used for demethoxylation, cause a statistical distribution of the resulting free carboxyl groups along the GalA backbone, treatment with pPME results in a block-wise distribution (Ralet, Dronnet, Buchholt, \& Thibault, 2001; Ralet \& Thibault, 2002). Chemical modification is often accompanied by a cleaving of the GalA backbone and resulting pectins have a reduced molecular weight and different techno-functional properties (Ralet et al., 2002). In contrast, application of purified plant or fungi PME with no or only small side activities causes nearly no depolymerisation.

Interactions with water are essential for the physical stability of pectin and its application (Elizalde, Pilosof, \& Bartholomai, 1996). On the one hand, contact with moisture during transport and storage of pectin considerably influences the powder properties (Einhorn-Stoll, Benthin, Zimathies, Görke, \& Drusch, 2015). On the other hand, pectin powders have to be dispersed and dissolved prior to any application. Despite the good final solubility of pectins, several technological operations such as mixing with sugar, stirring or heating are necessary in order to prevent lump formation and to achieve quick pectin dissolution (Rolin, 2002). Different aspects of pectin-water interactions can be tested by different methods. Nowadays, water sorption performed through the determination of sorption isotherms is most commonly applied (Panchev, Slavov, Nikolova, \& Kovacheva, 2010; Galus, Turska, \& Lenart, 2012; Kurita, Miyake, \& Yamasaki, 2012; Basu, Shivhare, \& Muley, 2013). In addition, the capillary sucking method (Baumann method) in a modified form (Wallingford \& Labuza, 1983) is still in use. Both methods have recently been applied and compared for different commercial citrus pectins (Einhorn-Stoll et al., 2015). Water sorption is the uptake of small amounts of water from the surroundings and adsorption at the surface or in micro-pores of pectin powder particles. It is based on moisture transfer by gas diffusion and gives relevant information for pectin storage and transport. The capillary sucking method offers a surplus of water, comparable to pectin suspension and dissolution processes. The water can creep also into macro-capillaries and interparticle voids, the pectin particles can swell and start to dissolve (Elizalde et. al., 1996). The more 
porous pectin particles are, the more water they can take up and, normally, the earlier their dissolution starts. Thus, the capillary sucking method allows conclusions on the pectin dissolution behaviour. The water uptake of pectin is generally assumed to depend on three main factors:

(I) The number of hydrophilic groups determines the amount of water that can be bound via hydrogen bridges.

(II) Close contact of the dissolved pectin macromolecules during modification promotes the formation of inter- and intramolecular bonds and a more compact structure of the particles after drying.

(III) Small particles and a rough surface after drying, milling and sieving increase the water uptake by sorption.

These assumptions are supported also by previous differential scanning calorimetry (DSC) investigations of pectin-water interactions with different pectin types (Einhorn-Stoll, Hatakeyama, \& Hatakeyama, 2012).

Type and intensity of pectin macromolecule interactions during modification are helpful, too, for explaining the stability against thermal degradation in thermal analysis (Einhorn-Stoll \& Kunzek, 2009). The thermal stability generally decreased with demethoxylation (Einhorn-Stoll, Kunzek, \& Dongowski, 2007) but, in a direct comparison, LMP demethoxylated under alkaline conditions were thermally less stable than acidic-treated LMP. The difference was ascribed mainly to the reaction conditions: Under acidic conditions (treatment with $\mathrm{HCl}$ at $\mathrm{pH}$ around 1) the newly formed free carboxyl groups were mostly undissociated and able to form hydrogen bonds between neighboured macromolecules. That caused a more compact structure in dry state. Under alkaline conditions (modification with potassium carbonate at $\mathrm{pH}$ around 10) monovalent cations were bound to the newly formed dissociated carboxyl groups and kept the dissolved pectin macromolecules in a certain distance. That caused a less compact structure in dry state. A comparable effect was described before for pectin containing apple fibre (Schalow \& Kunzek, 2004).

In recent publications was reported that commercial modified pectins with similar molecular parameters, such as degree of methoxylation and intrinsic viscosity (IV), differed in their physicochemical and techno-functional properties in thermal degradation, water uptake or the gelation process (Einhorn-Stoll, Kastner, \& Senge, 2012; Kastner, Einhorn-Stoll, \& Senge, 2012; EinhornStoll et al., 2015). It was assumed that these differences were caused by the specific demethoxylation methods and technological conditions of different suppliers, but the detailed processing parameters where unknown.

Therefore, the aim of the present work is the examination of the influence of different well-controlled pectin demethoxylation procedures on the physico-chemical and techno-functional properties. Model pectins were prepared from one commercially available high-metholxylated pectin, using 
plant or microbial pectinmethylesterases and hydrochloric acid, respectively. These model pectins were examined with respect to their thermal stability and their water uptake behaviour. It was hypothesized that different molecular interactions in the liquid state during demethoxylation affect the physical structure of the dried pectin, which leads to differences in thermal stability and water uptake.

\section{Materials and methods}

A commercially available non-standardised high-methoxylated (HM) citrus pectin (CP Kelco, Lille Skensved, Denmark), named as original pectin OP68 C, was demethoxylated in order to prepare different model pectins of high and low DM and a varying (block-wise or statistical) distribution of the free carboxyl groups. According to the demethoxylation method they are coded with $P$ for treatment with plant-derived $P M E, F$ for fungal $P M E$ and $A$ for acidic demethoxylation. $A$ total number of six different pectins with either high DM (P57, F56, A57) or low DM (P40, F42 and A42) were investigated. Additionally, the commercial pectin OP68 C was dissolved, precipitated and dried in the same way like the demethoxylated samples in order to achieve comparable material properties resulting from drying and milling. This sample was very similar to the commercial pectin with respect to the molecular parameters and only small alterations of the material properties. It will be used as reference pectin in the presented work and is named as OP68. All chemicals used were of analytical grade.

\subsection{Preparation of model pectins}

For enzymatic demethoxylation, two types of pectinmethylesterase (PME) were used, fungal PME (fPME) Fructozym Flot from Aspergillus niger (Erbslöh, Geisenheim, Germany) and orange plant PME (pPME), prepared from orange peel in the laboratory according to Arbaisah, Asbi, Junainah, \& Jamilah (1997) and Kim, Teng, \& Wicker (2005). A pH-stat method, based on Williams, Foster, \& Schols (2003) and Limberg, Körner, Buchholt, Christensen, Roepstorff, \& Mikkelsen (2000) was applied, using a 902 Titrando with a 800 Dosino and a $50 \mathrm{~mL}$ dosing unit (Deutsche METROHM $\mathrm{GmbH} \&$ Co. KG, Filderstadt, Germany). The pH of the pectin solution (1\%) was adjusted with $\mathrm{NaOH}$ to the optimum of 7.4 for the pPME and to 4.4 for the fPME, respectively. After demethoxylation, the $\mathrm{pH}$ of the solution was decreased to 3.0-3.5 and the solution was heated at $90^{\circ} \mathrm{C}$ for $10 \mathrm{~min}$ in order to stop the process and to inactivate the enzyme.

Acidic demethoxylation was performed in $0.5 \mathrm{M}$ or $1 \mathrm{M}$ hydrochloric acid for HMP and LMP, respectively, as described in Einhorn-Stoll, Glasenapp, \& Kunzek (1996). The pectin was dissolved in distilled water (1\%) and kept for a certain time at room temperature.

The model pectins from both procedures were precipitated from the solution with $95 \mathrm{vol} \%$ ethanol (ethanol:water $=4: 1$ ) and the precipitate was washed at least five times with 95 vol\% ethanol for 
water-ethanol exchange and removal of the chloride ions from the acidic-treated samples. The moist precipitate was coarsely grinded and dried in a laboratory oven at $50^{\circ} \mathrm{C}$ for $3 \mathrm{~h}$. Afterwards, the samples were milled in a centrifugal mill (Retsch, Haan, Germany) to a defined particle size The HMP were prepared first and milled to $<120 \mu \mathrm{m}$. This caused a undesirable heating of the powder and therefore the later prepared LMP were milled only to $<250 \mu \mathrm{m}$.

\subsection{Analytical characterisation of the model pectins}

The galacturonan content and degree of methoxylation were determined colorimatrically by the m-hydroxydiphenyl method (Blumenkrantz \& Asboe-Hansen, 1973; and the chromotropic acid method (Baeuerle, Otterbach, Gierschner \& Baumann, 1977), respectively. The intrinsic viscosity was examined according to Einhorn-Stoll, Salazar, Jaafar and Kunzek (2001) with a rolling ball micro viscosimeter LOVIS 2000M (Anton Paar GmbH, Ostfildern-Scharnhausen, Germany) as described by Mende, Peter, Bartels, Dong, Roehm, \& Jaros (2013) using a 1.59 mm capillary. The density of the pectin solutions was measured using a density meter DMA38 (Anton Paar, Germany). The ash content was determined in a muffle furnace at $525^{\circ} \mathrm{C}$. From the ash the sodium content was determined with a flame photometer Jenway PFP7 (Jenway, Staffordshire, USA) according to Vetter \& Kunzek (2003).

The physical properties of the pectin powder particles were characterized with different methods. The physical state (amorphous or crystalline) was determined by X-ray analysis with a Bruker D 5005 diffractometer with SolX detector (Bruker Corp., Billerica MA, USA). Porosity (pore size as well as inter-particle voids) was examined using a mercury porosimeter (Autopore III, Micromeritics Instruments Corp., Norville GA, USA) with pressure from 0 to $150 \mathrm{MPa}$ and mercury filling pressure of $0.004 \mathrm{MPa}$. Scanning electron microscopy (SEM) was performed at the central microscopy unit of the TU Berlin using the S-2700 scanning electron microscope (Hitachi, Japan) after sputtering the samples with gold. The micrographs allow a qualitative evaluation of the powder particle form and surface morphology.

\subsection{Thermal analysis}

A simultaneous thermal analysis as combined differential scanning calorimetry DSC and thermogravimetry TG was carried out using a STA 409 C device (Netzsch, Selb, Germany) as described in Einhorn-Stoll \& Kunzek (2009): linear heating rate of $10 \mathrm{~K} / \mathrm{min}$ from 20 to $450{ }^{\circ} \mathrm{C}$, dynamic inert nitrogen atmosphere $(75 \mathrm{~mL} / \mathrm{min}), 85 \mu \mathrm{L}$ platin crucibles without lid and with an empty crucible as reference. Sample weight was approximately $20 \mathrm{mg}$ and all runs were performed at least in duplicate. The differential thermogravimetry (DTG) curve was calculated as the first derivation from the TG curve. The extrapolated onset, peak and offset temperatures, the peak width $(\Delta T)$ and 
the maximum degradation velocity $\left(v_{\max }\right)$ were calculated with the Netzsch software as shown in Einhorn-Stoll et al. (2007).

\subsection{Characterisation of the pectin-water interactions}

Water uptake by sorption (WUS) and water uptake by capillary sucking (WUC) were examined as described in detail in Einhorn-Stoll et al. (2015). Prior to the examination of the WUS, all pectin samples were stored at room temperature in a desiccator containing $\mathrm{P}_{2} \mathrm{O}_{5}$ as a drying agent for exactly one week in order to minimize their water content. The WUS method represents the end point of the determination of sorption isotherms at $a_{w}$ about 1.0. It was performed in triplicate and parallel in three different desiccators at $30^{\circ} \mathrm{C}$ in a laboratory oven (temperature profile was validated prior to measurements). $0.1500 \mathrm{~g}$ of pectin were homogeneously distributed in a pre-dried petri dish (inner diameter $19 \mathrm{~mm}$ ) and placed in a desiccator above a constant volume of distilled water for $24 \mathrm{~h}$. The samples were weighed to $0.0001 \mathrm{~g}$ and the WUS was calculated as:

$W U S=\frac{m_{w}-m_{s}}{m_{S}} \cdot(g / g)$

with $m_{w}=$ mass of the wet sample and $m_{s}=$ mass of the dry pectin sample.

The water uptake by the capillary sucking method (WUC) was performed using a Baumann apparatus as described by Heinevetter and Kroll (1982). In this method the samples suck water from a water reservoir through a glass filter plate. A wet filter paper was placed between sample and glass filter plate, as suggested by Wallingford \& Labuza (1983), in order to reduce or at least to delay blocking of the glass filter plate by partly dissolved and swollen pectin particles. For each measurement 5 to $10 \mathrm{mg}$ of dry pectin sample were distributed as a thin layer on the wet filter paper. The water uptake was determined in defined intervals until (I) the value in the capillary was constant for $10 \mathrm{~min}$ or (II) it started to decrease because of partial dissolution of the pectin (end point criteria). The WUC was calculated by means of a calibration curve and considering the blank value as:

$W U C=\frac{m_{w}-m_{w b}}{m_{s}} \cdot(g / g)$

with $m_{w}=$ water uptake of the sample, $m_{w b}=$ water uptake of the filter paper and $m_{s}=$ dry mass of the pectin sample. All measurements were performed at least in duplicate at $20^{\circ} \mathrm{C}$.

\subsection{Statistical analysis}

A statistical analysis for correlations between the physico-chemical properties was made as regression analysis using Statgraphics 4.1 (Dittrich und Partner, Solingen, Germany). 


\section{Results}

\subsection{Analytical characterisation of the model pectins}

The results for the molecular parameters of the pectin samples are summarised in Table 1. There were differences in the galacturonan content and intrinsic viscosity within the two pectin groups. The galacturonan contents of F56 and A57 were higher than those of all other samples. The intrinsic viscosity of the acidic-treated pectins differed from those of the enzymatic-treated, but not in a similar way. The value was lower for A57 and higher for A42 than for the corresponding P- and F-samples.

Table 1 Analytical parameters of the pectin samples. $D M=$ degree of methoxylation, $G C=$ galacturonan content, $I V=$ intrinsic viscosity.

\begin{tabular}{|c|c|c|c|c|c|c|c|c|}
\hline Sample & Method & Type & $\begin{array}{l}\text { DM } \\
\text { (\%) }\end{array}$ & $\begin{array}{l}\text { GC } \\
(\%)\end{array}$ & $\begin{array}{c}\text { IV } \\
\left(\mathrm{cm}^{3} / \mathrm{g}\right)\end{array}$ & $\begin{array}{l}\text { Ash } \\
(\%)\end{array}$ & $\begin{array}{c}\mathrm{Na}^{+} \\
(\mathrm{mg} / \mathrm{g})\end{array}$ & $\begin{array}{l}\text { Hg poros } \\
(\mathrm{mL} / \mathrm{g})\end{array}$ \\
\hline OP68 C & none & HMP & 68 & 83.1 & 538.2 & 2.19 & 10.53 & 59.44 \\
\hline OP68 & washed & HMP & 68 & 87.0 & 524.9 & 2.31 & 10.78 & 74.63 \\
\hline P57 & pPME & HMP & 57 & 86.5 & 503.0 & 4.47 & 21.40 & 67.85 \\
\hline F56 & fPME & HMP & 56 & 94.2 & 530.0 & 2.81 & 12.58 & 70.80 \\
\hline A57 & acid & HMP & 57 & 93.9 & 421.0 & 0.21 & 0.50 & 60.47 \\
\hline P40 & pPME & LMP & 40 & 84.9 & 238.8 & 5.72 & 25.07 & \\
\hline F42 & fPME & LMP & 42 & 78.0 & 297.8 & 5.70 & 24.25 & \\
\hline A42 & acid & LMP & 42 & 81.7 & 413.7 & 0.11 & 0.14 & \\
\hline
\end{tabular}

Despite of the precipitation of pectin and intensive washing steps after demethoxylation, a considerable amount of sodium ions $(12-25 \mathrm{mg} / \mathrm{g}$ ) was detected in the enzymatic-treated pectin samples (Fig. 1). Their sodium content was higher in the LMP than in the HMP. There were, however, also differences between the P-and F-pectins of the same DM. These were high in case of the HMP but rather small in case of the LMP. In contrast the acidic-treated pectin samples contained only low amounts of sodium $(<0.5 \mathrm{mg} / \mathrm{g})$.

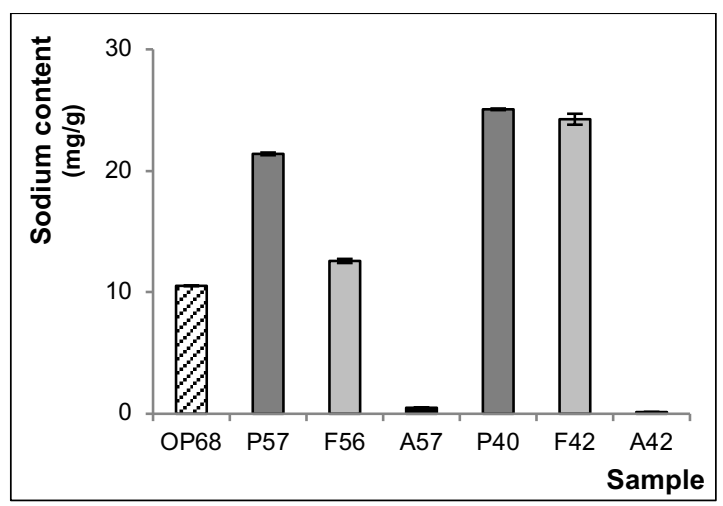

Fig. 1 Sodium content of the pectin samples. 
The influence of the modification on the physical state (X-ray analysis) was very small for the HMP. It was visible in case of the LMP but no distinct peaks of crystallised material could be found. The enzymatic-treated P40 and F42 were rather similar but a less homogeneous baseline with an increased hump at $16^{\circ}$ was detected in A42 (data are not shown). SEM micrographs revealed clear differences in particle shape of the HMP. The acidic-treated samples appeared as round or spherical particles with a rather smooth surface, whereas the enzymatic-treated particles were more irregular and fibrous in structure (Fig. 2). Since these differences in particle morphology were not observed in the LMP samples, mercury porosimetry was used to characterise the porosity only of the HMP. Mercury intrusion was about 13\% higher for the enzymatic-treated samples than for the acidic-treated.

a
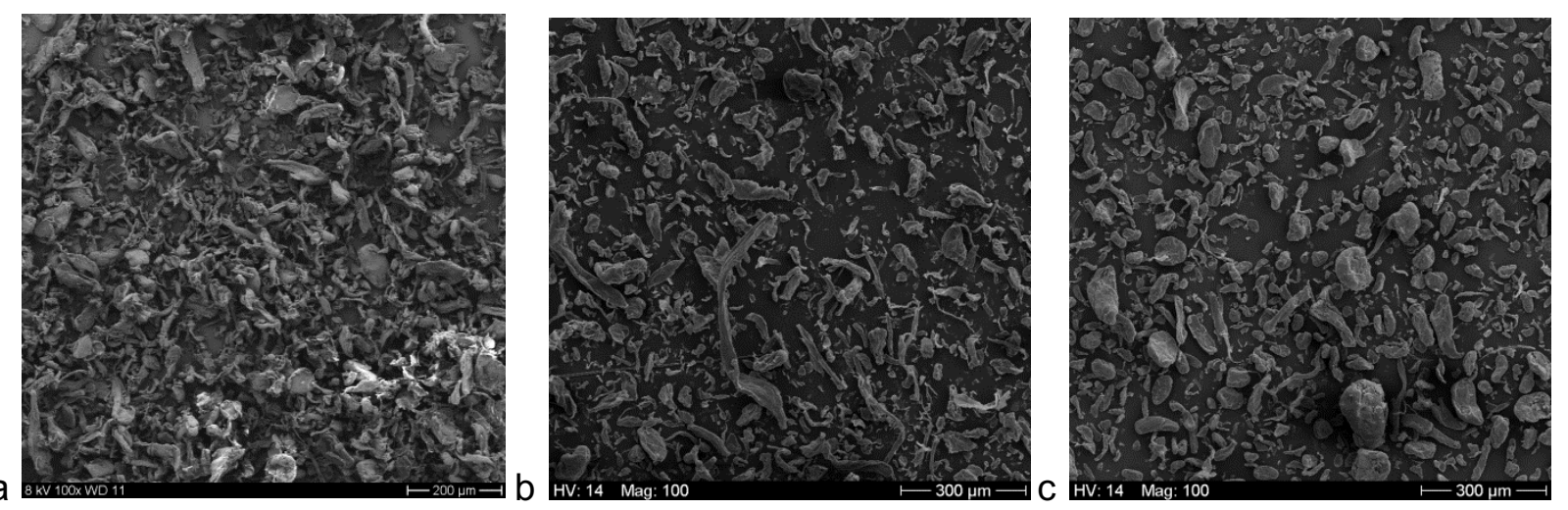

Fig. 2 REM of the particles of the high methoxylated pectins. a: P57, b: F56, c: A57. 


\subsection{Thermal analysis}

A DSC curve shows whether a thermal degradation reaction is exothermic or endothermic. The signals of pure pectin samples are always well-defined exothermic peaks. The DTG curve, the first derivative of the TG signal, reflects the thermal stability of the sample and the velocity of the weight loss. A low onset-temperature in the DTG indicates a low stability of a material and the peak height is proportional to the maximum degradation velocity. The DTG peak width is an indicator for the sample homogeneity with a peak broadening in inhomogeneous samples. These parameters of pectin thermal degradation give a good insight into their material properties. The results of the duplicate measurements were very similar and sometimes even identical.

Table 2 Results of the thermal analysis of the pectin samples. $T_{p}$ DSC $=$ peak temperature in the DSC-signal, $T_{\text {on DTG }}=$ extrapolated onset temperature in the DTG-signal, $T_{p}$ DTG = peak temperature in the DTG-signal, $\Delta T=$ peak width, $v_{\text {max }}=$ maximum degradation velocity.

\begin{tabular}{lcccccc}
\hline Sample & $\begin{array}{c}\mathbf{T}_{\mathbf{p} \text { DSC }} \\
\left({ }^{\circ} \mathbf{C}\right)\end{array}$ & $\begin{array}{c}\mathbf{T}_{\text {on DTG }} \\
\left({ }^{\circ} \mathbf{C}\right)\end{array}$ & $\begin{array}{c}\mathbf{T}_{\mathbf{p} \text { DTG }} \\
\left({ }^{\circ} \mathbf{C}\right)\end{array}$ & $\begin{array}{c}\mathbf{T}_{\text {off DTG }} \\
\left({ }^{\circ} \mathbf{C}\right)\end{array}$ & $\begin{array}{c}\Delta \mathbf{T} \\
(\mathbf{K})\end{array}$ & $\begin{array}{c}v_{\max } \\
(\mathbf{K} / \mathbf{m i n})\end{array}$ \\
\hline OP68 C & 243.1 & 220.7 & 239.4 & 253.6 & 32.9 & 17.23 \\
OP68 & 244.6 & 220.9 & 240.8 & 254.7 & 33.8 & 17.81 \\
P57 & 236.8 & 214.6 & 233.2 & 247.4 & 32.8 & 16.22 \\
F56 & 244.9 & 220.7 & 240.6 & 254.6 & 33.9 & 16.57 \\
A57 & 270.7 & 239.5 & 260.2 & 281.5 & 42.0 & 15.10 \\
& & & & & & \\
P40 & 240.2 & 214.4 & 235.4 & 249.1 & 34.7 & 14.88 \\
F42 & 241.6 & 211.4 & 235.1 & 252.5 & 41.1 & 12.95 \\
A42 & 271.9 & 234.3 & 257.2 & 283.2 & 48.9 & 12.21 \\
\hline
\end{tabular}

In the present study, the DSC and DTG data of the modified pectin samples differed from those of the original pectin as well as within the group of the modified pectin samples (Table 2 and Fig. 3a-d). The DSC curves of the enzymatic-treated samples had a similar shape like OP68, all showing a single well-defined exothermic signal. The DSC curves of the acidic-treated pectin samples, however, showed a strong endothermic pre-peak prior to the exothermic degradation as it was found for acidic-treated pectins in a previous study (Einhorn-Stoll \& Kunzek, 2009).

The DTG-curves of the enzymatic demethoxylated pectin samples showed a shift to the left side in comparison to OP68, which indicates that pectin degradation started earlier and samples were less stable. The differences were more pronounced for LMP P40 and F42 than for HMP P57 and F56, though a stronger influence on the smaller particles of the HMP might be expected. In addition, differences in the peak shift between pPME- and fPME-treated pectin samples were observed. These differences were more pronounced for HMP and rather small for LMP. The pectin samples demethoxylated under acidic conditions, A57 and A42, showed a completely different behaviour. Their DTG peaks shifted strongly to the right, indicating an increased thermal stability compared to 
OP68. In addition, the material became more inhomogeneous (increase in peak width) and the degradation velocity was reduced (decrease in peak height).

HMP

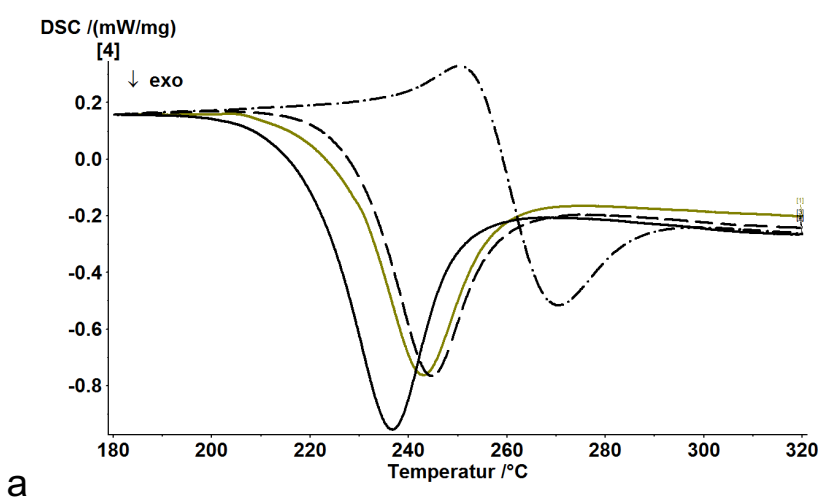

DTG $/(\% / \mathrm{min})$

C

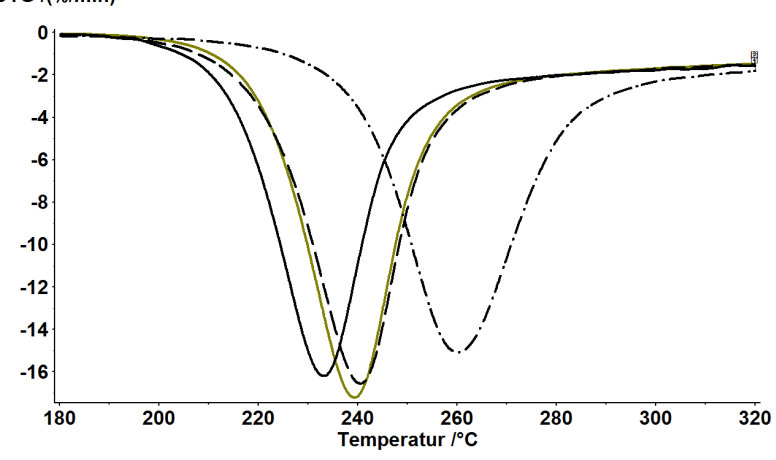

LMP

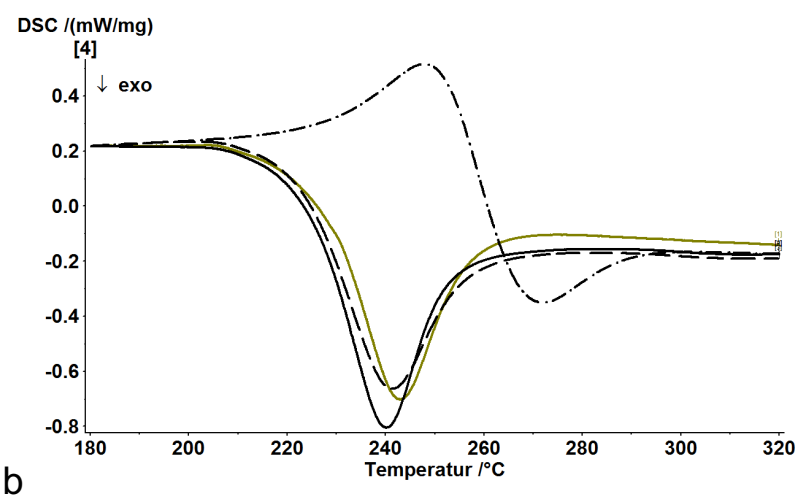

DTG /(\%/min)

d

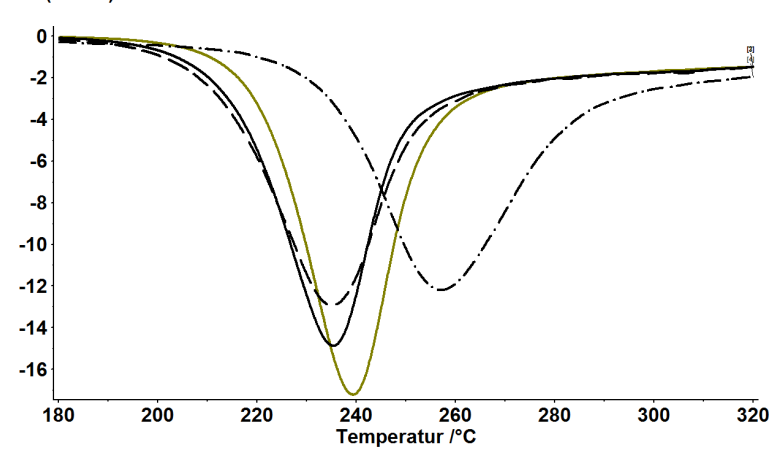

Fig. 3 Thermal analysis of the pectin samples. a, $c=$ high methoxylated pectin, $b, d=$ low methoxylated pectins; $a, b=D S C$ curves, $c, d=D T G$ curves. Grey full line = original pectin, black full line $=P$-pectins, $-\cdots=F$-pectins, .$---=a-p e c t i n s$.

\subsection{Pectin-water interactions}

The results of the two methods applied for the examination of pectin-water interactions varied considerably because their measuring principles are completely different.

The water uptake by sorption (WUS) ranged from 0.5 to $0.6 \mathrm{~g} / \mathrm{g}$ with significant differences between the modified pectin samples (Table 3 and Fig. 4). The enzymatic-treated pectin samples generally sorbed more water from the environment than the original pectin OP68 and also more water than the corresponding acidic-treated pectin samples. The order was P57 > F56 > A57 and P40 > F42 > A42. Moreover, all HMP showed a lower water uptake than the corresponding LMP, despite the smaller HMP particles would be expected to sorb more water. 


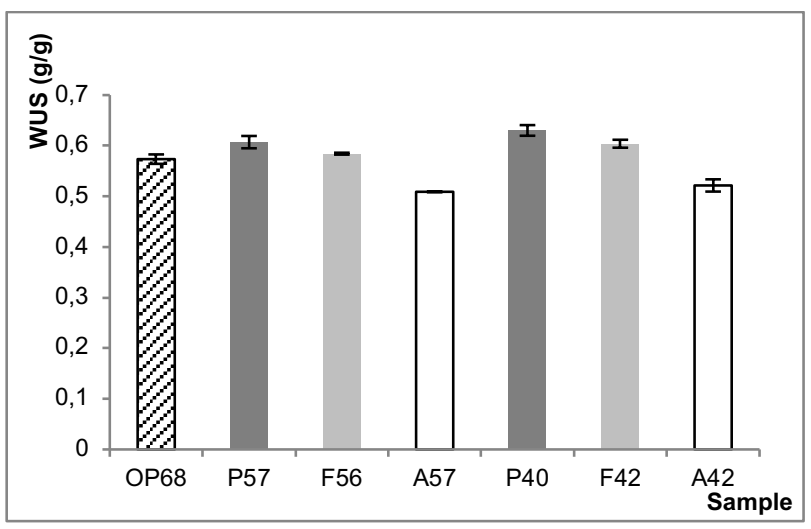

Fig. 4 Water uptake by sorption of the pectin samples.

The results of the capillary sucking method (WUC) include the final values of the amount of water taken up by the sample as well as the time required for the sorption (Table 3, Fig. 5). The final water uptake differed in a wide range between 9 and $48 \mathrm{~g} / \mathrm{g}$ as well as the time, ranging from 40 to 80 min. The WUC of the demethoxylated HMP samples was lower than the WUC of OP68. The opposite was observed for LMP samples, their WUC was much higher than the WUC of OP68. Acidic-treated pectin samples showed the highest WUC, followed by the pPME-treated. The fPMEtreated pectin samples had the lowest WUC and also a significantly shorter water uptake time than the other modified pectins.

Table 3 Results of the examination of pectin-water interactions. DM = degree of methoxylation, WUS = water uptake by sorption, $W U C=$ water uptake by capillary sucking.

\begin{tabular}{lccccc}
\hline Sample & $\begin{array}{c}\text { WUS } \\
(\mathbf{g} / \mathbf{g})\end{array}$ & $\begin{array}{c}\text { WUS } \\
\mathbf{\pm}\end{array}$ & $\begin{array}{c}\text { WUC } \\
(\mathbf{g} / \mathbf{g})\end{array}$ & $\begin{array}{c}\text { WUC } \\
\mathbf{\pm}\end{array}$ & $\begin{array}{c}\text { Sucking time } \\
(\mathbf{m i n})\end{array}$ \\
\hline OP68 C & 0.568 & 0.007 & 14.13 & 0.11 & 45 \\
OP68 & 0.573 & 0.009 & 10.78 & 0.32 & 60 \\
P57 & 0.607 & 0.012 & 9.66 & 0.01 & 70 \\
F56 & 0.584 & 0.002 & 6.45 & 0.36 & 40 \\
A57 & 0.509 & 0.001 & 12.47 & 0.69 & 70 \\
P40 & 0.630 & 0.011 & 24.13 & 1.22 & 70 \\
F42 & 0.604 & 0.008 & 21.47 & 0.52 & 50 \\
A42 & 0.521 & 0.012 & 48.92 & 0.00 & 80 \\
\hline
\end{tabular}

Statistical analysis revealed several correlations between the material properties of the tested samples. There was a negative correlation between sodium content and thermal stability $\left(R^{2}=0.92\right)$, and a positive correlation between sodium content and water uptake by sorption $\left(R^{2}=0.95\right)$. Also a good correlation between WUS and thermal stability was observed $\left(R^{2}=0.93\right)$. 
No correlation was found for the results of the two methods characterising the water uptake or for WUC and any other parameter.
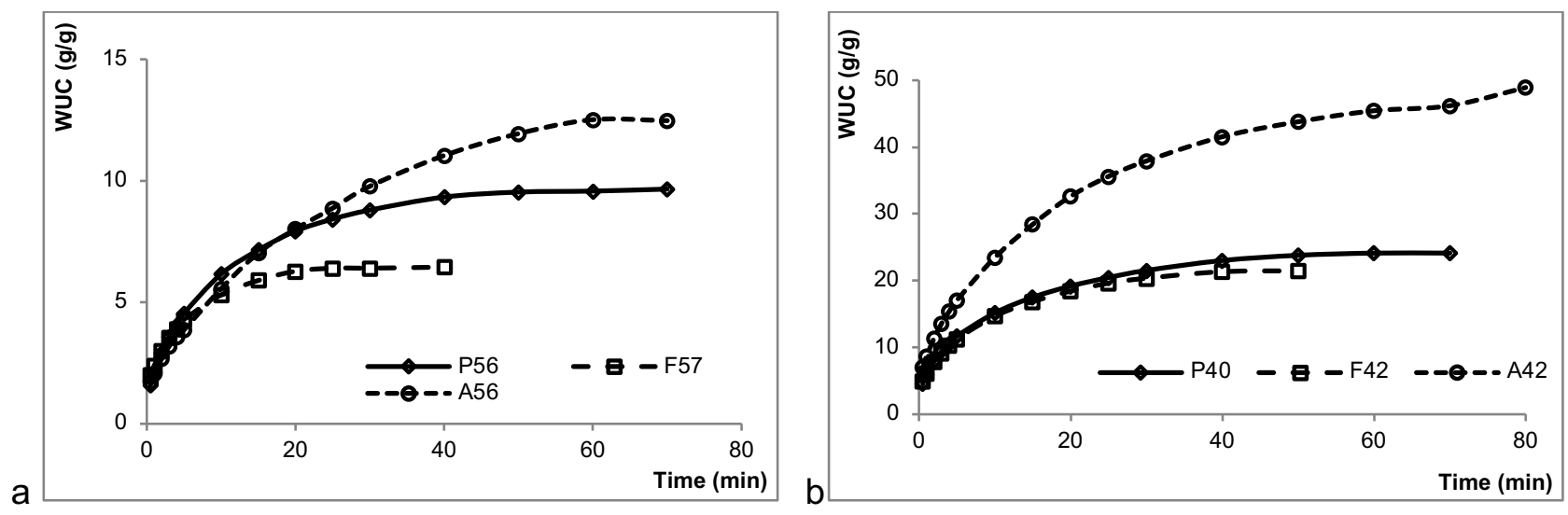

Fig. 5 Water uptake of the pectin samples during the capillary sucking procedure. $a=H M P, b=L M P$.

\section{Discussion}

For an understanding of the results it is necessary to discuss the mechanisms and different process conditions for demethoxylation and their impact on the chemical and physical structure (Table 4). Enzymatic demethoxylation was performed at the optimum $\mathrm{pH}$ for the enzyme activity: $\mathrm{pH} 4.4$ for the fPME and 7.4 for the pPME, respectively. The $\mathrm{pH}$ of the dissolved original pectin was 3.4 and sodium hydroxide was added in order to reach the optimum $\mathrm{pH}$. With increasing $\mathrm{pH}$ the number of dissociated free carboxyl groups increases and reaches $50 \%$ at the $\mathrm{pK}_{\mathrm{a}}$ (apparent $\mathrm{pK}$ of the pectin samples), which is about 3.5 - 4.5, depending on the charge density of the polymers (Rolin, 2002; Ralet et al., 2002). Sodium ions may bind to these dissociated groups. With increasing $\mathrm{pH}$ the number of carboxylic binding sites increases too and therefore was much higher at $\mathrm{pH} 7.4$ (reaction optimum of the pPME) than at $\mathrm{pH} 4.4$ (reaction optimum of the fPME). This is a possible explanation for the higher sodium content in the pPME-treated P57 in comparison with the fPME-treated F56. This effect is intensified during the demethoxylation process: $\mathrm{NaOH}$ is continuously added during the reaction in order to keep the $\mathrm{pH}$ constant and an increasing number of methoxyl groups are transformed to free carboxyl groups. A certain proportion of these carboxyl groups dissociates and binds added sodium ions. The increase in sodium content of the LMP P40 and F42 in comparison with the HMP P57 and F56 can be explained by the increased total number of free carboxyl groups during the more intense demethoxylation process.

In addition, the $\mathrm{pH}$ during demethoxylation has a strong effect on the interactions of the pectin macromolecules in solution. At $\mathrm{pH}<3.5$ (below the $\mathrm{pK}_{\mathrm{a}}$ ) free carboxyl groups are mainly undissociated and at $\mathrm{pH}>4.5$ (above $\mathrm{pK}_{\mathrm{a}}$ ) they are mainly dissociated. This means that the carboxyl groups were mainly undissociated during the acidic treatment at $\mathrm{pH} 1.5$, partly dissociated 
during demethoxylation with fPME ( $\mathrm{pH} 4.4)$ and mainly dissociated during methoxylation with pPME ( $\mathrm{pH}$ 7.4). The effect of different $\mathrm{pH}$ on the interactions of dissolved pectin macromolecules was first shown by circular dichroism by Plaschina, Braudo, and Tolstogusov (1978) and later on by Lutz, Aserin, Wicker, and Garti (2009).

Table 4 Pectin demethoxylation - influence of the modification method on the formation of pectin properties.

\begin{tabular}{|c|c|c|c|}
\hline Modification & Acidic & fungi PME & plant PME \\
\hline $\mathrm{pH}$ & 1.5 & 4.4 & 7.4 \\
\hline Carboxyl groups & Mainly undissociated $-\mathrm{COOH}$ & Partly dissociated -COO- & Strongly dissociated $-\mathrm{COO}$ \\
\hline Na-ions & - & + & ++ \\
\hline Macromolecule interaction & Hydrogen bonds & $\begin{array}{l}\text { Moderate repulsion, binding of } \\
\mathrm{Na}^{+}\end{array}$ & $\begin{array}{l}\text { Stronger repulsion, binding } \\
\mathrm{Na}^{+}\end{array}$ \\
\hline
\end{tabular}

Hydrogen bonds between undissociated and uncharged carboxyl groups at low $\mathrm{pH}$ favour strong interactions between pectin macromolecules (Plaschina et al., 1978; Ström, Schuster, \& Goh, 2014). In contrast, dissociated carboxyl groups at higher $\mathrm{pH}$ are negatively charged and cause electrostatic repulsion of the macromolecules. Lutz et al. (2009) report stronger interactions at pH 2 than at $\mathrm{pH} 6$, resulting from the effect of $\mathrm{pH}$ on the dissociation of the carboxylic groups.

Electrostatic binding of positively charged sodium ions to the dissociated groups (Ralet et al., 2002) can partly compensate the repulsion (Morris, Nishinari, \& Rinaudo, 2012; Ström et al., 2014). However, there seems to be a different binding of sodium cations to pectin samples with a more block- wise or more statistical distribution of the carboxyl groups (Ström et al., 2014; Yoo, Fishman, Savary, \& Hotchkiss, 2003). Furthermore, sodium ions might act as "spacers" between neighboured pectin macromolecules, partly comparable to side- branches of neutral sugars (Hwang \& Kokini, 1992), which keep the macromolecules at a certain distance and limit their interactions. The molecular interactions of dissolved pectins are able to affect the physical structure of the dried pectin particles and can explain the differences in techno-functionality.

\subsection{Effect of acidic demethoxylation}

The effect of the acidic treatment on the techno-functional properties has been broadly examined in the past (e.g. Garnier, Axelos, \& Thibault, 1993) and also material properties of powderous pectin samples have already been investigated (Einhorn-Stoll \& Kunzek, 2009; Einhorn-Stoll, Kastner, \& Drusch, 2014; Einhorn- Stoll, Prinz, \& Drusch, 2014). Purification, i.e. a decrease of the total ion content and an increase of the galacturonan content, is a typical side effect during acidic demethoxylation (Einhorn-Stoll \& Kunzek, 2009). A certain degree of depolymerisation is possible, in the present work it was only small for the HMP and more pronounced for the LMP. 
The endothermic pre-peak observed in the DSC curves in acidic-treated pectin samples might result from a conformational change from ${ }^{4} \mathrm{C}_{1}$ to the ${ }^{1} \mathrm{C}_{4}$, as it was suggested by Einhorn-Stoll and Kunzek (2009). The increase in thermal stability (shift of the DTG-peak to the right) can be ascribed to the newly-formed intermolecular hydrogen bonds and the more compact structure as described above. As a consequence, the acidic demethoxylated samples are rather inhomogeneous (broader degradation peaks than all other pectins, Fig. 3c,d). A certain degree of crystallinity as described before (Einhorn-Stoll, Hatakeyama, et al., 2012) could not be detected in the HMP (data not shown), but alterations, resulting from the stronger intermolecular interactions, were found in the LMP. In case of the HMP, the smooth particle surface (Fig. 2c) and the lower rate of mercury intrusion indicates a more compact particle structure than in the original pectin.

The pectin-water interactions of the acidic-treated pectin samples markedly varied in dependence on the examination method. Whereas their WUS was lowest, their WUC was high for HMP A57 and extremely high for the A40. This behaviour is in agreement with recent results from acidic-treated commercial LMP (Einhorn- Stoll et al., 2015) and can be explained by the two mechanisms of the water uptake. The acidic-treated samples adsorbed only small amounts of water on the smooth surface (WUS) and showed very late or no dissolution in WUC, because a certain amount of water was first necessary to break the intermolecular hydrogen bounds. During the prolonged time of analysis, the samples were able to bind a higher amount of water by swelling than the other model pectin samples. An intense acidic treatment resulted in pectins with a high number of undissociated free carboxyl groups. This caused stronger intermolecular interactions as well as longer and higher water uptake in comparison to the other tested pectin samples.

\subsection{Effect of the enzymatic demethoxylation}

In the present study, the two groups of enzymatic-treated pectins showed not only a markedly differing behaviour than the acidic-treated pectin samples, they differed also between each other. The effect of carboxyl group dissociation and sodium ion binding during demethoxylation (Fig. 1) strongly affects their material properties. Electrostatic repulsion and spacer-like action of the sodium ions caused a less compact powder structure with many small irregularly shaped and partly fibrous particles (Fig. 2). This structure in general accelerated the thermal degradation of the enzymatictreated pectins as indicated by the shift of the DTG-peak to a lower onset temperature (Table 2, Fig. 3). A similar effect has been described for pectins methoxylated under alkaline conditions, their DTG peaks shifted in a similar way to a lower onset temperature of thermal degradation with decreasing DM (Einhorn-Stoll et al., 2007). In the present study, there were also differences in the thermal analysis between the LMP and the HMP as well as between the pPME- and fPME-treated pectin samples. The enzyme- related differences are more pronounced for the HMP and rather small for the LMP, resulting from the varying sodium content. pPME-treated HMP had a much 
higher sodium content than fPME-treated HMP and therefore a less compact particle structure, which was more easily degraded.

The WUS of the enzymatic-treated pectin samples was higher than the WUS of the acidic-treated samples. More water could be adsorbed to the larger outer and inner surface of the less compact pectin particles as reflected by the difference in porosity. This effect was supported by the higher sodium content of the enzymatic-treated pectins, which was more pronounced for the P- than for the F-pectin samples. It is well-known that sodium ions are able to bind water (Mancinelli, Botti, Bruni, \& Ricci, 2007), and therefore the high sodium content, especially in case of P57, contributed to this effect, too. The WUC also differed between the P-pectin samples and the F-pectin samples. On the one hand, the fPME-treated pectin samples started earlier to dissolve and took up less water than the pPME-treated samples, but on the other hand the differences became smaller with decreasing DM. It can be assumed that a block-wise distribution of the demethoxylated carboxyl groups in P57 allowed a stronger intermolecular interaction in comparison to F56. A more compact structure in P57 favoured swelling and weakening with increasing water uptake instead of rapid dissolution as in F56. P-pectin samples behaved in this case partly like acidic-treated pectin but with a different type of molecular interaction. The two LMP samples, P40 and F42, however, had both so many newlyformed carboxyl groups that intermolecular interactions and swelling and weakening behaviour were similar.

One aim of the present study was it to evaluate possible similarities between the results of different analytical methods of the pectin samples by statistical analysis. An important result of the regression analysis was the correlation between the thermal stability ( $T_{\text {on DTG }}$ ) and the water uptake by sorption (WUS). This is a result of the strong dependence of both methods on the sodium content of the samples and its impact on the particle structure. The water uptake by capillary sucking depended on so many factors that there was no simple correlation to any other parameter. This was found also by Wallingford and Labuza (1983). 


\section{Conclusions}

The type of demethoxylation strongly influenced the material properties of model pectins. In general, a high $\mathrm{pH}$ during demethoxylation causes a high proportion of dissociated carboxyl groups. Electrostatic repulsion of negatively charged dissociated carboxyl groups in pectin macromolecules at $\mathrm{pH} 4.4$ and 7.4 is partly suppressed by sodium ions, but these ions also act like "spacers" and keep the macromolecules in a certain distance. As a result, there are less intermolecular interactions between undissociated carboxyl groups via hydrogen bonds and the particle structure is also less compact. Both factors result in a lower thermal stability and an increased water binding during sorption. The differences between acidic and enzymatic demethoxylated pectins were considerable at both examined degrees of methoxylation.

Comparing the effect of the two types of pectinmethylesterase, the difference in the distribution of the carboxyl groups was more important at high DM than at low DM. Results from the present study furthermore suggest, that sodium binding to the P-pectin samples was different from that to the F-pectin samples. It is likely that stronger intermolecular interactions are formed between the blocks in pectins with blockwise distribution of the carboxyl groups (P-pectin), providing more stability against particle dissolution in the presence of excess water.

The results of the methods to characterise water uptake can give valuable information for the application of pectin in food processing, especially during storage and dissolution. It can be concluded from water uptake by sorption that enzymatically demethoxylated pectin would adsorb water from the environment faster than pectin modified under acidic conditions. As a consequence, these types of pectin more easily tend to form lumps, which could be hardly dissolved afterwards. In terms of pectin dissolution, pectin demethoxylated with fungal PME shows only limited swelling but dissolves more easily, whereas acidic treated pectin binds a high amount of water before dissolution starts. 


\section{Acknowledgements}

The authors would like to thank Susann Engelmann, Enrico Raemisch and Anni Schütze for pectin sample preparation, Astrid Kliegel for the skilled pectin analysis and Oliver Görke (Technische Universität Berlin, Institute of Materials Science and Technologies) for X-ray measurements.

\section{List of special abbreviations}

$\begin{array}{ll}\text { A-pectin } & \text { pectin demethoxylated with acid } \\ \text { DM } & \text { degree of methoxylation } \\ \text { DSC } & \text { differential scanning calorimetry } \\ \text { DTG } & \text { differential thermogravimetry } \\ \text { F-pectin } & \text { pectin demethoxylated with fPME } \\ \text { fPME } & \text { fungi pectinmethylesterase } \\ \text { GC } & \text { galacturonan content } \\ \text { HMP } & \text { high-methoxylated pectin } \\ \text { IV } & \text { intrinsic viscosity } \\ \text { LMP } & \text { low-methoxylated pectin } \\ \text { OP / OP C } & \text { original pectin / original commercial pectin } \\ \text { P-pectin } & \text { pectin demethoxylated with pPME } \\ \text { pPME } & \text { plant pectinmethylesterase } \\ \text { PW } & \text { peak width } \\ \text { SEM } & \text { scanning electron microscopy } \\ \text { TA } & \text { thermal analysis } \\ \text { TG } & \text { thermogravimetry } \\ \text { Tp } & \text { peak temperature of the DSC or DTG signal } \\ \Delta T & \text { peak broadening } \\ \text { Vmax } & \text { maximum degradation velocity } \\ \text { WUS } & \text { water uptake by sorption } \\ \text { WUC } & \text { water uptake by capillary sucking }\end{array}$




\section{References}

Arbaisah, S., Asbi, B., Junainah, A., \& Jamilah, B. (1997). Purification Properties of Pectinesterase from Soursoup (Anona Muricata) Pulp. Food Chemistry, 59, 33-40.

Baeuerle, D., Otterbach, G., Gierschner, K. \& Baumann, G. (1977). Bestimmungen des Polyuronidgehaltes und des Veresterungsgrades des Pectinanteiles in Handelspektinpräparaten, Apfelsäften und Apfelmaceraten. Dtsch. Lebensm. Rundschau, 73, 281-286.

Basu, S., Shivhare, U.S. \& Muley, S. (2013). Moisture adsorption isotherms and glass transition temperature of pectin. J. Food Science and Technology, 50, 585-589.

Blumenkrantz, N. \& Asboe-Hansen, G. (1973). New method for quantitative determination of uronic acids. Analytical Biochemistry, 54, 484-489.

Einhorn-Stoll, U., Glasenapp, N. \& Kunzek, H. (1996). Modified pectins in whey protein emulsions. Nahrung/Food 40, 60-67.

Einhorn-Stoll, U., Salazar, T., Jaafar, B. \& Kunzek, H. (2001). Thermodynamic compatibility of sodium caseinate with different pectins. Influence of the milieu conditions and pectin modifications. Nahrung/Food, 45, 334-337.

Einhorn-Stoll, U., Kunzek, H. \& Dongowski, G. (2007). Thermal analysis of chemically and mechanically modified pectins. Food Hydrocolloids, 21, 1101-1112.

Einhorn-Stoll, U. \& Kunzek, H. (2009). Thermoanalytical characterisation of processing-dependent structural changes and state transitions of citrus pectin. Food Hydrocolloids, 23, 40-52.

Einhorn-Stoll, U., Hatakeyama, H. \& Hatakeyama, T. (2012). Influence of pectin modification on water binding properties. Food Hydrocolloids, 27, 494-502.

Einhorn-Stoll, U., Kastner, H. \& Senge, B. (2012). Comparison of molecular parameters, material properies and gelling behaviour of commercial citrus pectins. In P.A. Williams \& G.O. Phillips (Eds.), Gums and Stabilisers for the Food Industry 16 (pp.199-206). Cambridge, U.K.: Royal Society of Chemistry, RSC Special Publication No. 335.

Einhorn-Stoll, U., Kastner, H. \& Drusch, S. (2014). Thermally induced degradation of citrus pectins during storage - Alterations in molecular structure, colour and thermal analysis. Food Hydrocolloids, 35, 565-575.

Einhorn-Stoll, U., Prinz, C. \& Drusch, S. (2014). Influence of storage on the water binding of pectin: Determination by DSC. In: Gums and Stabilisers for the Food Industry 17, (pp. 147-154). Cambridge, U.K.: Royal Society of Chemistry, RSC Special Publication No. 346. 
Einhorn-Stoll, U., Benthin, A., Zimathies, A., Görke, O. \& Drusch, S. (2015). Pectin-water interactions: Comparison of different analytical methods and influence of storage. Food Hydrocolloids, 43, 577-583.

Elizalde, B.E., Pilosof, A.M.R. \& Bartholomai, G.B. (1996). Empirical model for water uptake and hydration rate of food powders by sorption and Baumann methods. J. Food Science, 61, 407409.

Galus, S., Turska, A. \& Lenart, A. (2012). Sorption and wetting properties of pectin edible films. Czech. J. Food Science, 30, 446-455.

Garnier, C., Axelos, M. \& Thibault, J.-F. (1993). Phase diagrams of pectin-calcium systems: Influence of $\mathrm{pH}$, ionic strength, and temperature on the gelation of pectin with different degrees of methylation. Carbohydrate Research, 240, 219-232.

Heinevetter, L. \& Kroll, J. (1982). Zur Bestimmung der Wasserbindung pulverförmiger quellfähiger Substanzen mittels einer Kapillarsaugmethode, Die Nahrung, K17-K18.

Hwang, J. \& Kokini, J.L. 1992. Contribution of the side branches to rheological properties of pectins. Carbohydrate Polymers, 19, 41-50.

Kastner, H., Einhorn-Stoll, U. \& Senge, B. (2012). New parameters fort he examination of the pectin gelation process. In P.A. Williams \& G.O. Phillips (Eds.), Gums and Stabilisers for the Food Industry 16 (pp.199-206). Cambridge, U.K.: Royal Society of Chemistry, RSC Special Publication No. 335.

Kim, Y., Teng, Q. \& Wicker, L. (2005). Action Pattern of Valencia Orange PME De-esterification of High Methoxyl Pectin and Characterization of modified Pectins. Carbohydrate Research, 340, 2620-2629.

Kurita, O., Miyake, Y. \& Yamazaki, E. (2012). Chemical modification of citrus pectin to improve its dissolution in water. Carbohydrate Polymers, 87, 1720-1727.

Laurent, M.A. \& Boulenguer, P. (2003). Stabilization mechanism of acid dairy drinks (ADD) induced by pectin. Food Hydrocolloids, 17, 445-454.

Limberg, G., Körner, R., Buchholt, H., Christensen, T., Roepstorff, P. \& Mikkelsen, J. (2000). Analysis of different de-esterfications mechanisms for pectin by enzymatic fingerprinting using endopectin lyase and endopolygalacturonase II from A. Niger. Carbohydrate Research, 327, 293-307.

Lutz, R. Aserin, A. Wicker, L., \& Garti, N. (2009). Structure and physical properties of pectins with block-wise distribution of carboxylic acid groups. Food Hydrocolloids, 23, 786-794. 
Mancinelli, R., Botti, A., Bruni, F. \& Ricci, M.A. (2007). Hydration of sodium, potassium, and chloride ions in solution and the concept of structure maker/breaker. Journal of Physical Chemistry, 111, 13507-13577.

Mende, S., Peter, M., Bartels, K., Dong, T., Roehm, H. \& Jaros, D. (2013). Concentration dependent effects of dextran on the physical properties of acid milk gels. Carbohydrate Polymers, 98(2), 1389-1396.

Morris, E.R., Nishinari, K. \& Rinaudo,M. (2012). Gelation of gellan - A review. Food Hydrocolloids, 28, 373-411.

Panchev, I.N., Slavov, A., Nikolova, K. \& Kovacheva, D. (2010). On the water-sorption properties of pectin. Food Hydrocolloids, 24, 763-769.

Plaschina, I.G., Braudo, E.E., \& Tolstogusov, V.B., (1978). Circular dichroism studies of pectin solutions. Carbohydrate Research, 60, 1-8.

Ralet, M.-C., Dronnet, V., Buchholt, H.C. \& Thibault, J.-F., 2001. Enzymatically and chemically deesterified lime pectins: characterisation, polyelectrolyte behavior and calcium binding properties. Carbohydrate Research, 336, 117-125.

Ralet, M.-C. \& Thibault, J.-F., 2002. Interchain heterogeneity of enzymatically deesterified lime pectins. Biomacromolecules, 3, 917-925

Rolin, C. (2002). Commercial pectin preparations. In: G.B. Seymour \& J.P. Knox (Eds.), Pectins and their Manipulation (pp. 222-241). Oxford: Blackwell Publishing.

Rolin, C., Chrestensen, I. B., Hansen, K.M., Staunstrup, J. \& Sorensen, S. (2010). In P.A. Williams \& G.O. Phillips (Eds.), Gums and Stabilisers for the Food Industry 15 (pp.13-25). Cambridge, U.K.: Royal Society of Chemistry, RSC Special Publication No. 325.

Schalow, S. \& Kunzek, H. (2004). The influence of pre-drying treatment and of suspension solution conditions on the rehydration of apple cell wall materials. Eur. Food Res. Technol. 219, 329-340.

Ström, A., Schuster, E. \& Goh, S.M. (2014). Rheological characterisation of acid pectin samples in the absence and presence of monovalent cations. Carbohydrate Polymers, 113, 336-343.

Vetter, S. \& Kunzek, H. (2003). The influence of the pre-drying treatment on the hydration properties of dried cell wall materials from apples. Eur. Food Res. Technol., 216, 129-137.

Wallingford, L. \& Labuza, T.P. (1983). Evaluation of the water binding properties of food hydrocolloids by physical / chemical methods and in a low fat meat emulsion. J. Food Science, $48,1-5$. 
Williams, M.A.K., Foster, T.J. \& Schols, H.A. (2003). Elucidation of pectin methylester distribution by capillary electrophoresis. Journal of Agricultural and Food Chemistry, 51, 1777-1781.

Yoo, S.H., Fishman, M.L., Savary, B.J. \& Hotchkiss, A.T. (2003). Monovalent salt-induced gelation of enzymatically deesterified pectin. Journal of Agriculture and Food Chemistry, 51, 7410-7417. 